\title{
Genetic characterization of multidrug resistance in Shigella spp. from Japan
}

Correspondence

Tadashi Shimamoto

tadashis@hiroshima-u.ac.jp

Received 16 May 2006

Accepted 10 August 2006

\author{
Ashraf M. Ahmed, ${ }^{1,3}$ Kimi Furuta, ${ }^{2}$ Kei Shimomura, ${ }^{2}$ Yoshio Kasama ${ }^{2}$ \\ and Tadashi Shimamoto ${ }^{1}$
}

\author{
${ }^{1}$ Laboratory of Food Microbiology and Hygiene, Graduate School of Biosphere Science, \\ Hiroshima University, Higashi-Hiroshima 739-8528, Japan \\ ${ }^{2}$ Division of Biological Science, Hiroshima City Institute of Public Health, Hiroshima 733-8650, \\ Japan \\ ${ }^{3}$ Department of Microbiology, Faculty of Veterinary Medicine, Kafr El-Sheikh University, Kafr \\ El-Sheikh 33516, Egypt
}

\begin{abstract}
This study characterized the genetic basis of antimicrobial resistance of a number of Shigella spp. isolated from humans from 2000 to 2004 in Hiroshima prefecture, Japan. A total of 26 isolates of Shigella spp. were included in this study. Antimicrobial susceptibility tests revealed high levels of resistance, especially to ampicillin, streptomycin, trimethoprim, tetracycline, nalidixic acid and ciprofloxacin. PCR and DNA sequencing were used for screening and characterization of antibiotic-resistance determinants. PCR sequencing analysis revealed the presence of only one type of class 1 integron in one isolate of Shigella sonnei. This class 1 integron was 1904 bp and contained two gene cassettes: a probable esterase/lipase (est $X$ ) and aadA1, which confers resistance to streptomycin and spectinomycin. Two types of class 2 integron were identified in this study. One was the classic type (2158 bp) and carried the three conserved resistance gene cassettes of the class 2 integron, $d f r A 1$, sat1 and aadA1, which confer resistance to trimethoprim, streptothricin and streptomycin/spectinomycin, respectively. This type was detected in both Shigella sonnei (14 isolates) and Shigella flexneri (five isolates). The other type was shorter (1313 bp) and carried only two gene cassettes, dfrA1 and sat1. This integron was detected in a single isolate of Shigella sonnei. PFGE patterns showed limited diversity within clusters of the same species. Furthermore, an extended-spectrum $\beta$-lactamase gene, b/a OXA-30, which confers resistance to ampicillin, was characterized in all isolates of Shigella flexneri except the oldest strain, which was isolated in 2000. Southern blot hybridization and conjugation experiments showed that bla OXA-30 was located in the chromosome.
\end{abstract}

\section{INTRODUCTION}

Shigella is a major cause of dysentery throughout the world and is responsible for 5-10\% of diarrhoeal illnesses in many areas. There are four species of Shigella, Shigella dysenteriae, Shigella flexneri, Shigella boydii and Shigella sonnei, also designated groups A, B, C and D, respectively. Each year, $1 \cdot 1$ million people are estimated to die from Shigella infection (Kotloff et al., 1999). Recently, it was estimated that 91 million people worldwide contract shigellosis each year; in Asia, 410000 children, mostly malnourished, die (World Health Organization, 2005). In the USA, shigellosis is the

Abbreviations: CS, conserved segment; MDR, multidrug resistance.

The GenBank/EMBL/DDBJ accession numbers for the sequences of the Shigella sonnei class 1 integron, S. sonnei class 2 integron, Shigella flexneri class 2 integron, S. sonnei small-size class 2 integron and $S$. flexneri blaOXA-30 genes are AB234884, AB234885, AB234886, AB234887 and AB234888, respectively. third leading bacterial gastrointestinal disease, with 25000 cases reported in 1998 and 18000 cases reported in 1999 (Cimons, 2000). In Japan, according to the National Epidemiological Surveillance of Infectious Diseases, there were 471 notifications of shigellosis in 2003, 597 in 2004 and 560 in 2005, totalling 1628 cases (as of 6 February 2006) (National Institute of Infectious Diseases, 2006). A multiprefectural outbreak of Shigella sonnei infections associated with eating oysters occurred in Japan at the end of November 2001 (Terajima et al., 2004). A summary report of the Ministry of Health, Labour and Welfare stated that 160 cases of shigellosis had been reported from 30 different prefectures by 30 January 2002.

Problems associated with the development and spread of antibiotic resistance have been increasing since the early 1960 s and are currently viewed as a major threat to global public health (World Health Organization, 2001). The ability of bacteria to acquire and disseminate exogenous genes via 
Table 1. Oligonucleotides used in this study

\begin{tabular}{|c|c|c|c|}
\hline Primer & Nucleotide sequence $\left(5^{\prime} \rightarrow 3^{\prime}\right)$ & Target size & Reference/GenBank accession no. \\
\hline $5^{\prime}-\mathrm{CS}$ & GGCATCCAAGCAGCAAG & Variable & Lévesque et al. (1995) \\
\hline $3^{\prime}-\mathrm{CS}$ & AAGCAGACTTGACCTGA & & \\
\hline hep51 & GATGCCATCGCAAGTACGAG & & \\
\hline IntI2-F2 & GATCCTGCCATCATTGAGTA & Within class 2 integron & This study \\
\hline TEM-R & GACAGTTACCAATGCTTAATC & & \\
\hline SHV-F & TTATCTCCCTGTTAGCCACC & 795 bp & Weill et al. (2004) \\
\hline SHV-R & GATTTGCTGATTTCGCTCGG & & \\
\hline OXA-F & TCAACTTTCAAGATCGCA & $591 \mathrm{bp}$ & J02967 \\
\hline OXA-R & GTGTGTTTAGAATGGTGA & & \\
\hline
\end{tabular}

mobile genetic elements such as plasmids, transposons, insertion sequences and genomic islands has been the major factor in the development of multidrug-resistant strains (Rowe-Magnus et al., 2002). The matter became more serious after the discovery of another mechanism for the dissemination of resistance, involving integrons (Stokes \& Hall, 1989). Integrons are genetic elements that acquire and exchange exogenous DNA, known as gene cassettes, by a site-specific recombination mechanism (Stokes \& Hall, 1989). The most notable gene cassettes identified within integrons are those conferring resistance to antibiotics. The increasing incidence of multidrug-resistant micro-organisms has led to tremendous interest in the genetics and mechanisms of resistance evolved by bacteria to counteract the effects of antimicrobial agents. Recent reports have determined the molecular basis of multidrug-resistance (MDR) phenotypes of Shigella spp. in Australia (McIver et al., 2002), Ireland (DeLappe et al., 2003), Korea (Oh et al., 2003), Italy (Mammina et al., 2005) and Brazil (Peirano et al., 2005). However, there are no reports related to the molecular basis of these resistances in Japan. Hence, the aim of this study was to characterize the genetic basis of MDR phenotypes in clinical isolates of Shigella spp. in Japan.

\section{METHODS}

Bacterial strains. Twenty-six strains of Shigella spp. (Shigella sonnei, $n=17$; Shigella flexneri, $n=8$; Shigella boydii, $n=1$ ) were characterized in this study. These strains were the entire complement of the collection from stool samples of sporadic diarrhoeic patients in Hiroshima prefecture, Japan, from 2000 to 2004 and sent to the Division of Biological Science, Hiroshima City Institute of Public Health, for further analysis. The isolates were identified and serotyped by standard procedures (Murray et al., 1995). Selected resistant strains were stored in Luria-Bertani broth containing $50 \%$ glycerol at $-80^{\circ} \mathrm{C}$ until use.

Antimicrobial susceptibility testing. Antibiotic susceptibility testing was performed using the Kirby-Bauer disc susceptibility method according to National Committee for Clinical Laboratory Standards guidelines (NCCLS, 2002). Shigella spp. were tested for susceptibility to various antibiotics, including: ampicillin $(10 \mu \mathrm{g})$, chloramphenicol $(30 \mu \mathrm{g})$, ciprofloxacin $(5 \mu \mathrm{g})$, kanamycin $(30 \mu \mathrm{g})$, gentamicin $(10 \mu \mathrm{g})$, nalidixic acid $(30 \mu \mathrm{g})$, streptomycin $(10 \mu \mathrm{g})$, trimethoprim $(5 \mu \mathrm{g})$, tetracycline $(30 \mu \mathrm{g})$ and cefotaxime $(5 \mu \mathrm{g})$.

Bacterial DNA preparation, PCR and DNA sequencing of integrons. Preparation of the bacterial DNA template and PCR conditions for the detection of class 1 integrons have been described previously (Ahmed \& Shimamoto, 2004). The class 1 integron primers 5'-CS and 3'-CS (Table 1) (Lévesque et al., 1995), which amplify the region between the $5^{\prime}$-conserved segment $\left(5^{\prime}\right.$-CS) and $3^{\prime}$-CS of class 1 integrons, were used. For the detection of class 2 integrons, PCR was performed with the primer pair hep74 and hep51, specific to the conserved regions of class 2 integrons, as described elsewhere (DeLappe et al., 2003). Two other primers were then designed according to the preliminary DNA sequencing results for class 2 integrons (IntI2-F2 and IntI2-R2; Table 1). These primers were located within the PCR fragment and were used for complete sequencing of both DNA strands of the whole class 2 integron segment. PCR products were subjected to electrophoresis in a $1.0 \%$ agarose gel, stained with ethidium bromide and visualized under UV light. The PCR fragment was purified from the agarose gel using a QIAquick Gel Extraction kit (Qiagen). Both DNA strands of the PCR product were sequenced using an $\mathrm{ABI}$ automatic DNA sequencer (model 3730xl; Perkin-Elmer).

Screening for $\boldsymbol{\beta}$-lactamase-encoding genes. Shigella spp. were tested for the $\beta$-lactamase-encoding genes $b l a_{\mathrm{TEM}}, b l a_{\mathrm{SHV}}, b l a_{\mathrm{OXA}}$ and $b l a_{\mathrm{CTX}-\mathrm{M}}$ by PCR, as described previously (Bonnet et al., 2000; Siu et al., 2000; Weill et al., 2004). Universal primers for the $\beta$-lactamase-encoding genes were used (Table 1).

PFGE analysis. All isolates of Shigella spp. were analysed by PFGE with the restriction enzyme XbaI using standardized methods (Centers for Disease Control and Prevention, 2000). The DNA was separated by PFGE using the GenePath system (Bio-Rad). Following electrophoresis, gels were stained with $0.5 \mu \mathrm{g}$ ethidium bromide $\mathrm{ml}^{-1}$, illuminated under UV light and photographed. Macrorestriction fragment patterns were analysed according to the 
Table 2. Characteristic features of Shigella spp. used in this study

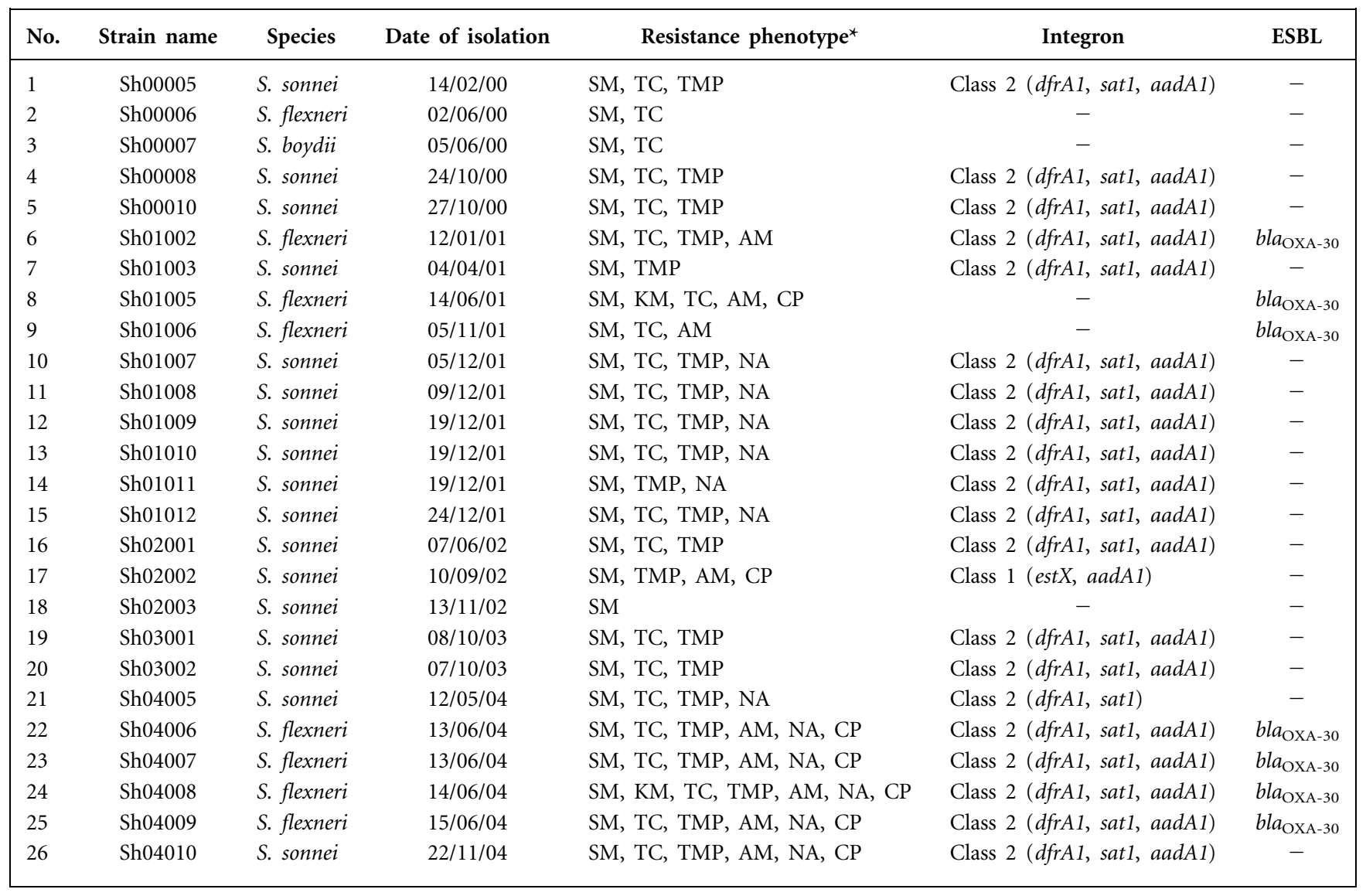

*AM, ampicillin; CP, ciprofloxacin; KM, kanamycin; NA, nalidixic acid; SM, streptomycin; TC, tetracycline; TMP, trimethoprim.

criteria of Tenover et al. (1995); isolates having PFGE patterns with differences in one to three bands were considered to be closely related.

Plasmid isolation, probe preparation and Southern blot hybridization. Plasmids were isolated from the most recent $b l a_{\mathrm{OXA}-30^{-}}$ positive strain of Shigella flexneri (Sh04009; Table 2) using the alkaline lysis method described by Sambrook \& Russell (2001). Horizontal gel electrophoresis was carried out using $0 \cdot 7 \%$ agarose gel in $1 \%$ TAE buffer at $100 \mathrm{~V}$ for $1 \mathrm{~h}$. After agarose gel electrophoresis, the DNA fragments in the gel were transferred to Hybond$\mathrm{N}^{+}$nylon membranes (Amersham Biosciences) according to the manufacturer's instructions. The DNA fragment containing the whole $b a_{\text {OXA-30 }}$ gene $(890 \mathrm{bp})$ was amplified by PCR using the $b l a_{\text {OXA-30 }}$ primers OXA-F-2 and OXA-R-2 (Table 1) and purified as described above. The purified fragment was labelled with alkaline phosphatase using an AlkPhos Direct Labelling System (Amersham Biosciences) and subsequently used as a DNA probe. All hybridization steps were carried out according to the manufacturer's protocol. Hybridization was performed at $55^{\circ} \mathrm{C}$ for $12 \mathrm{~h}$ and the hybridized DNA was detected using the CDP-Star chemiluminescent signal generation system (Amersham Biosciences) according to the manufacturer's instructions.

Conjugation experiments. A mating-out assay was carried out as described previously (Ahmed et al., 2005) using the bla $a_{\text {OXA-30-posi- }}$ tive strain of Shigella flexneri (Sh04009) as the donor strain and a rifampicin-resistant mutant of Escherichia coli HB101 obtained in vitro (Sambrook \& Russell, 2001) as the recipient strain. Transconjugants were selected on Mueller-Hinton agar containing $200 \mu \mathrm{g}$ rifampicin $\mathrm{ml}^{-1}$ and $100 \mu \mathrm{g}$ ampicillin $\mathrm{ml}^{-1}$.

Computer analysis of the sequence data. A similarity search was carried out using BLAST (http://www.ncbi.nlm.nih.gov/ blast/).

\section{RESULTS AND DISCUSSION}

\section{Emergence of multidrug-resistant Shigella spp. in Japan}

Antimicrobial therapy causes marked symptom improvement and shortens the duration of illness in Shigella infection (Salam \& Bennish, 1991; Mahoney et al., 1993). Previously, various types of antimicrobial agent have been effective for the treatment of shigellosis, but options for treatment of this disease are now becoming limited due to the emergence of multidrug-resistant strains of Shigella. Over the last decade, Shigella spp. have shown a pattern of steadily increasing resistance to antibiotics worldwide (Replogle et al., 2000; Lee et al., 2001; McIver et al., 2002; Oh et al., 2003). In Japan, many Shigella sonnei isolates were recently found to have MDR phenotypes to nalidixic acid, 
(a)

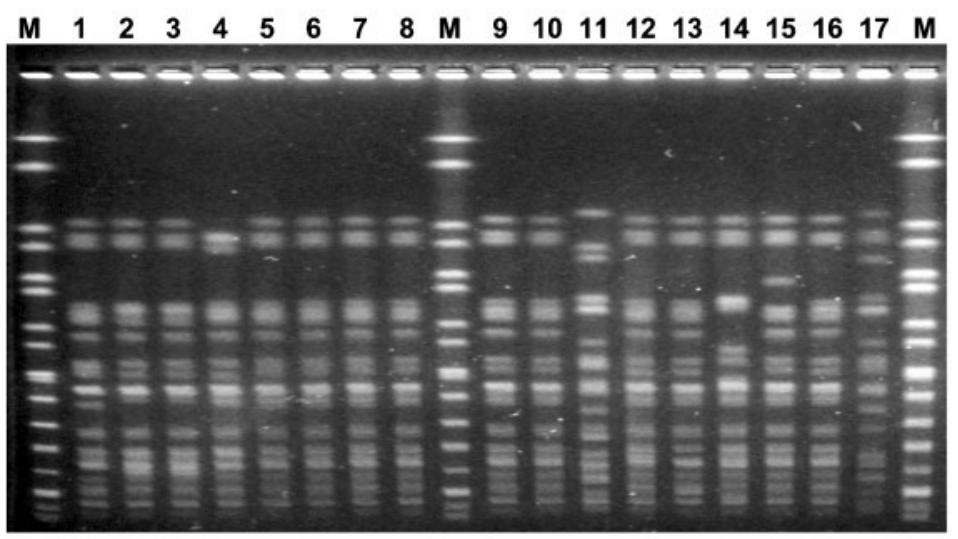

(b)

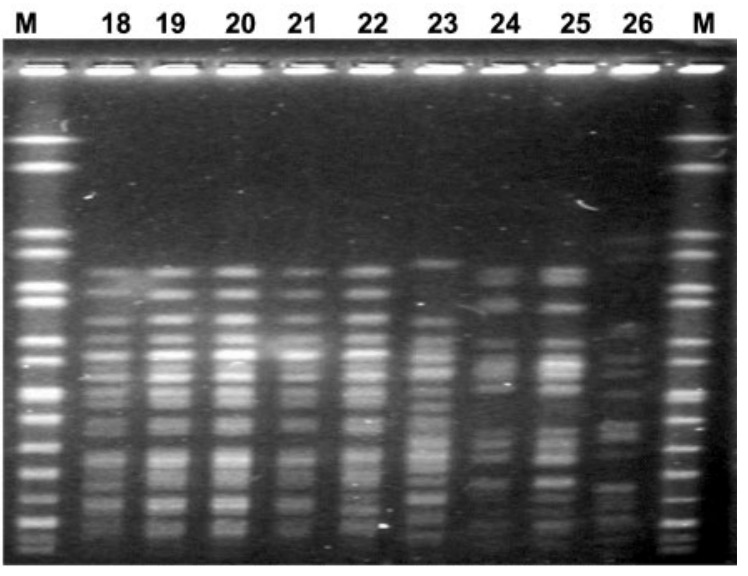

Fig. 1. PFGE patterns of Shigella spp. after Xbal digestion. (a) PFGE patterns of Shigella sonnei isolates. (b) Shigella flexneri isolates (lane 18-25) and a single isolate of Shigella boydii (lane 26). M, Size markers (DNA from Salmonella Braenderup $\mathrm{H} 9812$ digested with $\mathrm{Xbal}$ ).

tetracycline and trimethoprim/sulfamethoxazole (Hirose et al., 2005). In the present study, many isolates of Shigella spp., especially those isolated recently, were shown to have MDR phenotypes against ampicillin, streptomycin, trimethoprim, tetracycline, nalidixic acid and ciprofloxacin (Table 2).

PFGE patterns showed limited diversity within most clusters of the same species (Fig. 1). Over the last few years, similar MDR patterns in Shigella spp. have been reported in Ireland (DeLappe et al., 2003), India (Pazhani et al., 2004), Spain (Navia et al., 2005), Turkey (Ozmert et al., 2005) and the USA (Sivapalasingam et al., 2006). Hence, in order to ensure appropriate treatment for shigellosis, continual surveillance is required to determine which antibiotics are still active.

\section{Analysis of integron gene cassettes}

The capture and spread of antibiotic resistance determinants by integrons underlies the rapid evolution of MDR phenotypes among diverse, Gram-negative clinical isolates (Rowe-Magnus et al., 2002). Integrons encode an enzyme, termed integrase, that allows them to capture antibioticresistance gene cassettes (Stokes \& Hall, 1989). Of the different classes of MDR integrons that have been identified, integron classes 1 and 2 are the most common in Gram-negative bacteria (White et al., 2001). The structure of class 1 integrons includes the $5^{\prime}$ - and $3^{\prime}$-CS and a variable region. The organization of class 2 integrons is similar to that of class 1, but they are associated with transposon $\operatorname{Tn} 7$ and are known to carry three classic gene cassettes, dihydrofolate reductase $(d f r A 1)$, streptothricin acetyltransferase (sat1) and aminoglycoside adenyltransferase (aadA1), conferring resistance to trimethoprim, streptothricin and streptomycin/ spectinomycin, respectively (Hansson et al., 2002).
In this study, PCR and DNA sequencing results identified only one type of class 1 integron in a single isolate (Sh02002) of Shigella sonnei (Table 2). This isolate had a unique PFGE pattern (Fig. 1, lane 11). This integron was $1904 \mathrm{bp}$ and contained two gene cassettes. One was a probable esterase/ lipase (est $X)$ and the other was an aminoglycoside adenyltransferase (aadA1), which confers resistance to streptomycin and spectinomycin. Similar class 1 integrons of about $1955 \mathrm{bp}$ have been identified in Shigella sonnei isolated in Ireland (DeLappe et al., 2003). Moreover, in a recent report, a class 1 integron harbouring only one gene cassette, aadA1, was detected in a single isolate of Shigella sonnei from Brazil (Peirano et al., 2005). Two types of class 2 integron were identified in this study. One was the classic type (2158 bp) and carried the three conserved resistance gene cassettes of class 2 integrons, dfrAl, sat 1 and aadA1. This type was detected in both Shigella sonnei (14 isolates) and Shigella flexneri (five isolates). The other type was shorter (1313 bp) and carried only two gene cassettes, $d f r A 1$ and sat1. This integron was detected in an isolate (Sh04005) of Shigella sonnei that was isolated in 2004 (Table 2). The PFGE pattern of this isolate differed from that of the other cluster (Fig. 1, lane 14). This short integron has also been detected previously (but at a size of $1371 \mathrm{bp}$ ) in a single isolate of Shigella sonnei from Ireland (DeLappe et al., 2003). The low incidence of class 1 integrons and the high incidence of class 2 integrons in Shigella spp. in Japan consolidate previous results related to the incidence of these integrons in Shigella spp. from other countries such as Australia (McIver et al., 2002), Ireland (DeLappe et al., 2003), Korea (Oh et al., 2003), Italy (Mammina et al., 2005) and Brazil (Peirano et al., 2005). Although other mechanisms of resistance are possible, streptomycin and trimethoprim resistance are most likely attributable to expression from the genes contained in the corresponding integrons (Table 2). 


\section{Characterization of bla oxA-30}

Resistance to ampicillin in Gram-negative bacteria is primarily mediated by $\beta$-lactamases, which hydrolyse the $\beta$-lactam ring and thereby inactivate the antibiotic (Livermore, 1995). Many different $\beta$-lactamases have been described, but TEM-, SHV-, OXA- and CTX-M-type $\beta$ lactamases are predominant in Gram-negative bacteria (Bradford, 2001). Hence, Shigella spp. were examined for the presence of these $\beta$-lactamase-encoding genes using universal primers for each group (Table 1). PCR screening results showed that all isolates of Shigella spp. were negative for TEM-, SHV- and CTX-M $\beta$-lactamases, while all isolates of Shigella flexneri (except for the oldest strain, Sh00006, which was isolated in 2000) were positive for OXA-type $\beta$ lactamase (Table 2). Interestingly, the negative strain, Sh00006, had a unique PFGE pattern that distinguished it from the other Shigella flexneri strains by one missing band (Fig. 1, lane 23). In contrast, all isolates of Shigella sonnei were negative for OXA-type $\beta$-lactamase. PCR and DNA sequencing results using primers for the whole $b a_{\text {OXA }}$ gene (OXA-F-2 and OXA-R-2; Table 1) showed that this OXAtype $\beta$-lactamase was $100 \%$ identical to $b l a_{\mathrm{OXA}-30}$, which was originally discovered in Shigella flexneri strains isolated from Hong Kong and Shanghai, China, in 2000 (Siu et al., 2000) and was then detected in an isolate of Salmonella enterica serotype Typhimurium from an Australian patient (Hanson et al., 2002). OXA-type $\beta$-lactamases confer resistance to ampicillin and cephalothin and are characterized by their high hydrolytic activity against oxacillin and cloxacillin (Bradford, 2001). bla $a_{\mathrm{OXA}-30}$ is closely related to $b l a_{\text {OXA-1 }}$, differing in only one amino acid at codon 131 (AGA $\rightarrow$ GGA; Arg to Gly), and confers more resistance to cefepime than to ceftazidime (Siu et al., 2000). Southern blot hybridization using the most recent $b l a_{\mathrm{OXA}-30}$-positive strain of Shigella flexneri, Sh04009, showed that bla $a_{\text {OxA-30 }}$ was located in the chromosome (Fig. 2). The conjugation experiment results also supported the chromosomal location of $b l a_{\text {OXA-30 }}$, as no transconjugants were obtained on Mueller-Hinton agar containing rifampicin and ampicillin. The chromosomal location of $b l a_{\text {OXA-30 }}$ has been reported in Shigella flexneri strains isolated from Hong Kong and Shanghai (Siu et al., 2000). These results may explain the persistence of bla $a_{\mathrm{OXA}-30}$ in Shigella flexneri in overcoming the effects of ampicillin, which was among the antibiotics recommended by the World Health Organization for the treatment of bacillary dysentery (World Health Organization, 1995).

\section{PFGE patterns in relation to resistance phenotypes, integrons and blaoxA-30}

With the exception of the above-mentioned unique PFGE patterns for some strains, macrorestriction analysis by $\mathrm{XbaI}$ showed either indistinguishable or similar PFGE patterns (one or two band differences) among strains of the same species (Fig. 1). These PFGE patterns were associated with similar resistance phenotypes and the predominance of class 2 integrons in most strains of Shigella sonnei and Shigella

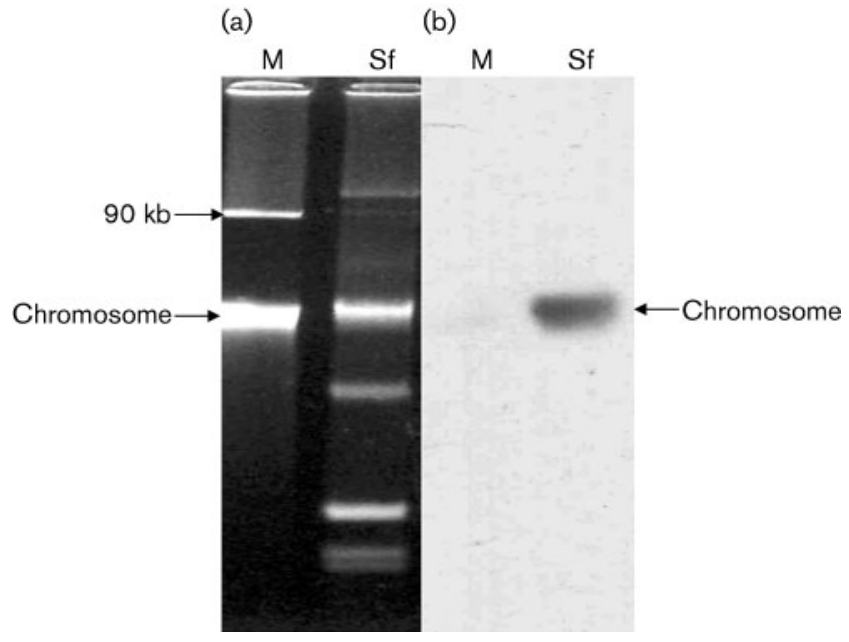

Fig. 2. Agarose gel electrophoresis (a) and Southern blot hybridization (b) of the blaOXA-30-positive strain of Shigella flexneri, Sh04009. M, Salmonella enterica serotype Typhimurium LT2 plasmid (90 kb) used as size marker; Sf, the plasmids of Shigella flexneri, including part of its chromosome. The hybridization signal is located in the chromosome.

flexneri and with $b l a_{\mathrm{OXA}-30}$ in all strains (except one) of Shigella flexneri (Table 2). These data suggest a clonal relatedness of strains of the same species, especially those isolated from the same locality (Hiroshima prefecture). Similar limited diversity in strains of Shigella spp. has been reported previously in Ireland (DeLappe et al., 2003), India (Pazhani et al., 2004) and Japan (Terajima et al., 2004).

\section{Conclusions}

In this study, we have characterized the molecular basis of the MDR phenotype of Shigella spp. for the first time in Japan. Our study focused on the analysis of class 1 and class 2 integron gene cassettes and also on $\beta$-lactamase-encoding genes. Class 2 integrons were found to be predominant in Shigella spp. and $b a_{\mathrm{OXA}-30}$ is reported for the second time in Shigella flexneri.

\section{ACKNOWLEDGEMENTS}

A.M.A. is supported by a postdoctoral fellowship from the Japan Society for the Promotion of Science. This work was supported by a Grant-in-Aid for Scientific Research to T.S. from the Ministry of Education, Culture, Sports, Science and Technology of Japan.

\section{REFERENCES}

Ahmed, A. M. \& Shimamoto, T. (2004). A plasmid-encoded class 1 integron carrying sat, a putative phosphoserine phosphatase gene and aadA2 from enterotoxigenic Escherichia coli O159 isolated in Japan. FEMS Microbiol Lett 235, 243-248.

Ahmed, A. M., Kawamoto, H., Inouye, K., Hashiwata, Y., Sakaki, M., Seno, M. \& Shimamoto, T. (2005). Genomic analysis of a 
multidrug-resistant strain of enterohaemorrhagic Escherichia coli O157: H7 causing a family outbreak in Japan. J Med Microbiol 54, 867-872.

Bonnet, R., Sampaio, J. L. M., Labia, R., De Champs, C., Sirot, D., Chanal, C. \& Sirot, J. (2000). A novel CTX-M $\beta$-lactamase (CTX-M8) in cefotaxime-resistant Enterobacteriaceae isolated in Brazil. Antimicrob Agents Chemother 44, 1936-1942.

Bradford, P. A. (2001). Extended-spectrum $\beta$-lactamases in the 21 st century: characterization, epidemiology, and detection of this important resistance threat. Clin Microbiol Rev 14, 933-951.

Centers for Disease Control and Prevention (2000). Standardized Molecular Subtyping of Foodborne Bacterial Pathogens by Pulsed-Field Gel Electrophoresis: Training Manual. Atlanta: Centers for Disease Control and Prevention.

Cimons, M. (2000). Rapid food-borne pathogen ID system is making a difference. ASM News 66, 617-619.

DeLappe, N., O'Halloran, F., Fanning, S., Corbett-Feeney, G., Cheasty, T. \& Cormican, M. (2003). Antimicrobial resistance and genetic diversity of Shigella sonnei isolates from western Ireland, an area of low incidence of infection. J Clin Microbiol 41, 1919-1924.

Hanson, N. D., Moland, E. S., Hossain, A., Neville, S. A., Gosbell, I. B. \& Thomson, K. S. (2002). Unusual Salmonella enterica serotype Typhimurium isolate producing CMY-7, SHV-9 and OXA-30 $\beta$ lactamases. J Antimicrob Chemother 49, 1011-1014.

Hansson, K., Sundström, L., Pelletier, A. \& Roy, P. H. (2002). IntI2 integron integrase in Tn7. J Bacteriol 184, 1712-1721.

Hirose, K., Terajima, J., Izumiya, H., Tamura, K., Arakawa, E., Takai, N. \& Watanabe, H. (2005). Antimicrobial susceptibility of Shigella sonnei isolates in Japan and molecular analysis of S. sonnei isolates with reduced susceptibility to fluoroquinolones. Antimicrob Agents Chemother 49, 1203-1205.

Kotloff, K. L., Winickoff, J. P., Ivanoff, B., Clemens, J. D., Swerdlow, D. L., Sansonetti, P. J., Adak, G. K. \& Levine, M. M. (1999). Global burden of Shigella infections: implications for vaccine development and implementation of control strategies. Bull World Health Organ 77, 651-666.

Lee, J. C., Oh, J. Y., Kim, K. S., Jeong, Y. W., Cho, J. W., Park, J. C., Seol, S. Y. \& Cho, D. T. (2001). Antimicrobial resistance of Shigella sonnei in Korea during the last two decades. APMIS 109, 228-234.

Lévesque, C., Piché, L., Larose, C. \& Roy, P. H. (1995). PCR mapping of integrons reveals several novel combinations of resistance genes. Antimicrob Agents Chemother 39, 185-191.

Livermore, D. M. (1995). $\beta$-Lactamases in laboratory and clinical resistance. Clin Microbiol Rev 8, 557-584.

Mahoney, F. J., Farley, T. A., Burbank, D. F., Leslie, N. H. \& McFarland, L. M. (1993). Evaluation of an intervention program for the control of an outbreak of shigellosis among institutionalized persons. J Infect Dis 168, 1177-1180.

Mammina, C., Pontello, M., Dal Vecchio, A., Nastasi, A. \& The Shigella sonnei Working Group (2005). Identification of Shigella sonnei biotype $g$ isolates carrying class 2 integrons in Italy (2001 to 2003). J Clin Microbiol 43, 2467-2470.

Mclver, C. J., White, P. A., Jones, L. A., Karagiannis, T., Harkness, J., Marriott, D. \& Rawlinson, W. D. (2002). Epidemic strains of Shigella sonnei biotype g carrying integrons. J Clin Microbiol 40, 1538-1540.

Murray, P. R., Baron, E. J., Pfaller, M. A., Tenover, F. C. \& Yolken, R. H. (editors) (1995). Manual of Clinical Microbiology, 6th edn. Washington DC: American Society for Microbiology.

National Institute of Infectious Diseases (2006). Shigellosis, Japan, 2003-2005. Infect Agents Surveillance Rep 27, 61-63.
Navia, M. M., Gascón, J. \& Vila, J. (2005). Analysis of the mechanisms of resistance to several antimicrobial agents in Shigella spp. causing travellers' diarrhoea. Clin Microbiol Infect 11, 1044-1047.

NCCLS (2002). Performance Standards for Antimicrobial Susceptibility Testing; 12th Informational Supplement. Document M100-S12. Wayne, PA: National Committee for Clinical Laboratory Standards.

Oh, J. Y., Yu, H. S., Kim, S. K., Seol, S. Y., Cho, D. T. \& Lee, J. C. (2003). Changes in patterns of antimicrobial susceptibility and integron carriage among Shigella sonnei isolates from southwestern Korea during epidemic periods. J Clin Microbiol 41, 421-423.

Ozmert, E. N., Gokturk, B., Yurdakok, K., Yalcin, S. S. \& Gur, D. (2005). Shigella antibiotic resistance in central Turkey: comparison of the years 1987-1994 and 1995-2002. J Pediatr Gastroenterol Nutr 40, 359-362.

Pazhani, G. P., Sarkar, B., Ramamurthy, T., Bhattacharya, S. K., Takeda, Y. \& Niyogi, S. K. (2004). Clonal multidrug-resistant Shigella dysenteriae type 1 strains associated with epidemic and sporadic dysenteries in eastern India. Antimicrob Agents Chemother 48, 681-684.

Peirano, G., Agerso, Y., Aarestrup, F. M. \& dos Prazeres Rodrigues, D. (2005). Occurrence of integrons and resistance genes among sulphonamide-resistant Shigella spp. from Brazil. J Antimicrob Chemother 55, 301-305.

Replogle, M. L., Fleming, D. W. \& Cieslak, P. R. (2000). Emergence of antimicrobial-resistant shigellosis in Oregon. Clin Infect Dis 30, $515-519$.

Rowe-Magnus, D. A., Guerout, A.-M. \& Mazel, D. (2002). Bacterial resistance evolution by recruitment of super-integron gene cassettes. Mol Microbiol 43, 1657-1669.

Salam, M. A. \& Bennish, M. L. (1991). Antimicrobial therapy for shigellosis. Rev Infect Dis 13, S332-S341.

Sambrook, J. \& Russell, D. (2001). Molecular Cloning: a Laboratory Manual, 3rd edn. Cold Spring Harbor, NY: Cold Spring Harbor Laboratory.

Siu, L. K., Lo, J. Y. C., Yuen, K. Y., Chau, P. Y., Ng, M. H. \& Ho, P. L. (2000). $\beta$-Lactamases in Shigella flexneri isolates from Hong Kong and Shanghai and a novel OXA-1-like $\beta$-lactamase, OXA-30. Antimicrob Agents Chemother 44, 2034-2038.

Sivapalasingam, S., Nelson, J. M., Joyce, K., Hoekstra, M., Angulo, F. J. \& Mintz, E. D. (2006). High prevalence of antimicrobial resistance among Shigella isolates in the United States tested by the National Antimicrobial Resistance Monitoring System from 1999 to 2002. Antimicrob Agents Chemother 50, 49-54.

Stokes, H. W. \& Hall, R. M. (1989). A novel family of potentially mobile DNA elements encoding site-specific gene-integration functions: integrons. Mol Microbiol 3, 1669-1683.

Tenover, F. C., Arbeit, R. D., Goering, R. V., Mickelsen, P. A., Murray, B. E., Persing, D. H. \& Swaminathan, B. (1995). Interpreting chromosomal DNA restriction patterns produced by pulsed-field gel electrophoresis: criteria for bacterial strain typing. J Clin Microbiol 33, 2233-2239.

Terajima, J., Tamura, K., Hirose, K., Izumiya, H., Miyahara, M., Konuma, H. \& Watanabe, H. (2004). A multi-prefectural outbreak of Shigella sonnei infections associated with eating oysters in Japan. Microbiol Immunol 48, 49-52.

Weill, F.-X., Demartin, M., Tandé, D., Espié, E., Rakotoarivony, I. \& Grimont, P. A. D. (2004). SHV-12-like extended-spectrum- $\beta$ lactamase-producing strains of Salmonella enterica serotypes Babelsberg and Enteritidis isolated in France among infants adopted from Mali. J Clin Microbiol 42, 2432-2437. 
White, P. A., Mclver, C. J. \& Rawlinson, W. D. (2001). Integrons and gene cassettes in the Enterobacteriaceae. Antimicrob Agents Chemother 45, 2658-2661.

World Health Organization (1995). Guidelines for the Control of Epidemics due to Shigella dysenteriae 1. Publication no. WHO/CDR/ 95.4. Geneva: World Health Organization.
World Health Organization (2001). Global Strategy for Containment of Antimicrobial Resistance. Publication no. WHO/CDS/CSR/DRS/ 2001.2a. Geneva: World Health Organization.

World Health Organization (2005). Shigellosis: disease burden, epidemiology and case management. Wkly Epidemiol Rec 80, 94-99. 